\title{
Hospitalizations and in-hospital outcomes in patients with ST-elevation myocardial infarction during the coronavirus disease 2019 pandemic: The Albanian experience
}

ORIGINAL INVESTIGATION

\begin{abstract}
Objective: Global studies report a significant decline in ST-elevation myocardial infarction (STEMI) related hospitalization rates during the coronavirus disease 2019 (COVID-19) pandemic outbreak. However, there have been several divergent reports on hospital outcomes. In this study, we aim to investigate the impact of the COVID 19 outbreak on hospitalizations because of STEMI and in-hospital outcomes in Albania.

Methods: This was a retrograde study, collecting data for hospitalizations because of STEMI from March 9, (first COVID 19 case in our country) to April 30, 2020, (period of total lockdown) compared with the same period in 2019 at our center. The incidence rate ratio (IRR) was used to compare admissions because of STEMI and procedures and the risk ratio $(R R)$ to compare mortality and other complication rates.
\end{abstract}

Results: Admissions for STEMI declined during the COVID-19 period from a total of 217 in 2019 to 156 in $2020(-28.1 \%)$ representing IRR $0.719(p=0.033)$. PCIs also reduced from 168 procedures in 2019 to 113 in $2020(-33 \%)$, representing an IRR of $0.67, p=0.021$. The time from symptom onset to arrival at our intensive care unit was significantly higher in 2020 compared to 2019 ( $925.6 \pm 1097$ vs. $438.7 \pm 385$ minutes, $p<0.001)$. The STEMI death rate during the pandemic compared to the control period was significantly increased to $14.1 \%$ vs. $7.8 \%(R R=1.91 \mathrm{p}=0.037$, but with no significant increase in primary $\mathrm{PCI}-\mathrm{STEM}$ leath rate ( $8.9 \%$ vs. $4.8 \% R R=1.85 p=0.217$ ). Cardiogenic shock also increased during the pandemic to $21.2 \%$ from $12.4 \%$ in 2019 ( $R R=1.70 p=0.025$ ).

Conclusion: Hospitalizations and revascularization procedures for STEMI significantly reduced during the COVID-19 pandemic. We identified a substantial increase in the STEMI mortality rate and cardiogenic shock during the pandemic outbreak. Delayed timely reperfusion intervention might be responsible for the increased risk for complications.

Keywords: ST-elevation myocardial infarction, coronavirus disease 2019 pandemic, hospitalizations, in-hospital outcomes, coronary interventions

\section{INTRODUCTION}

In December 2019, a case of pneumonia of unknown cause was reported in Wuhan, China (1). The infection caused by a newly identified coronavirus, severe acute respiratory syndrome coronavirus 2 (SARS-CoV-2) spread all over the world, causing the current pandemic of coronavirus 2019 disease (COVID-19) (2).

The Albanian government, progressively since March 09, 2020, (3) (the first case declared) urged and ordered physical distancing and strict movement restriction measures. Total containment measures; closure of all activities and restriction of movement except for healthcare workers and other vital services, began on March 16, 2020 (4). At the end of April 2020, Albania had a low COVID-19 incidence rate of 27/100,000 and a low mortality rate of $1.08 / 100,000$ inhabitants (5). The COVID-19 outbreak did not affect the structure and organization of hospital cardiac services in Albania. Patients suffering from COVID-19 have been treated in specialized hospital facilities.

The SARS-CoV-2 infection is associated with an increase in thrombotic complications and an inflammatory impact on atherosclerotic plaque progression $(6,7)$.

\author{
Leonard Simoni iD \\ Ilir Alimehmeti ${ }^{1}$ iD \\ Mirald Gina \\ Astrit Ceka (D) \\ Ermir Tafaj iD \\ Alban Dibra \\ Artan Goda (iD) \\ Department of Cardiology, University \\ Hospital Center "Mother Teresa"; Tirana- \\ Albania \\ 'Department of Occupational Health, \\ Faculty of Medicine, University of \\ Medicine; Tirana-Albania
}

Corresponding Author:

Leonard Simoni

$\triangle$ leonardsimoni@yahoo.com

Accepted: August 2, 2021 Available Online Date: February 2, 2022

Cite this article as: Simoni $L$, Alimehmeti I, Gina M, Ceka A, Tafaj E, Dibra A, et al. Hospitalizations and in-hospital outcomes in patients with ST-elevation myocardial infarction during the coronavirus disease 2019 pandemic: The Albanian experience. Anatol J Cardiol 2022; 26: 118-26.

DOI: 10.5152/AnatolJCardiol.2021.486 
Therefore, an increase in the incidence of ST-segment elevation myocardial infarction (STEMI) was expected. Global surveys and reports have shown a significant decrease in admissions (STEMI) (8-14) and associated invasive procedures (15-17), showing the collateral effect of the COVID-19 pandemic on patients with acute myocardial infarction and suggesting a variety of possible contributing factors. However, thus far, there have been several divergent reports on hospital outcomes, particularly mortality and cardiogenic $\operatorname{shock}(8,18-21)$.

Therefore, in this study, we aimed to assess the impact of the COVID-19 pandemic outbreak on STEMI hospitalizations and in-hospital management and outcomes in Albania.

\section{METHODS}

We conducted a single-center, observational, and retrospective study, including all the consecutive patients hospitalized for STEMI in the Department of Cardiology from March 9, 2020, (first day of application of social distance measures) to April 30, 2020, (a period of total lockdown with first release measures beginning in the last week of April (22) and continuing through May and June). This same period in 2019 was used as a control. All information was collected using the patients' medical files. STEMI was diagnosed using the $4^{\text {th }}$ Universal Definition of Myocardial Infarction criteria (23). The study complies with the Declaration of Helsinki and was approved by the Local Ethics Committee of the hospital. Informed consents were waived because of the retrospective nature of the study.

Demographic data, cardiovascular risk factors, previous comorbidities, and outcomes were collected. Coronary angiography was performed as per standard practice. Angiographic data regarding angiographic obstructive coronary artery disease (CAD), critical stenosis, number of affected vessels, and treated vessels and data obtained from revascularization procedures, such as percutaneous coronary intervention ( $\mathrm{PCI}$ ) or coronary artery bypass surgery (CABG) were analyzed.

\section{Admission, procedural, and in-hospital outcomes}

The primary outcome of this analysis was the overall rate and weekly incidence of admissions for STEMI during the study and control periods. Other outcomes analyzed and compared between the two periods included overall admissions

\section{HIGHLIGHTS}

- Containment measures and the fear of contracting the virus in healthcare settings during the coronavirus disease 2019 pandemic affected admissions and invasive interventions in patients with ST-elevated myocardial infarctions.

- The patients who were admitted showed worse conditions (later from the onset of symptoms, a higher level of troponin I, and a lower left ventricular ejection fraction), which explains the potential increase in mortality and cardiogenic shock.

- Public education and health service safety are the major challenges. for STEMI, proportion of patients undergoing coronary angiography and revascularization procedures ( $P C I$ or $C A B G)$, cardiac troponin I (cTnl) on admission (normal values 0.00$1.00 \mathrm{ng} / \mathrm{mL}$ ), time from symptom onset to intensive care unit (ICU), time from arrival in ICU to sheath insertion, left ventricular ejection fraction (at discharge), in-hospital all-cause mortality, cardiogenic shock, life-threatening arrhythmias, mechanical complications, stroke, stent thrombosis, and reinfarction. Changes in the rate of admissions for STEMI and related procedures were calculated by comparing the total admission/procedure number for the period 9th of March to 30 April 2020 with the number during 2019 and expressed as a percentage. Percentage changes in weekly STEMI admission and related procedures were calculated similarly by comparing the admission/procedure numbers of each week (starting with the first week from March 09 and the following 6 weeks until April 26, 2020) with the weekly number during 2019.

The rate ratio of STEMI admissions/procedures between the study period and the control period are shown as incidence rate ratios (IRR), which were calculated by comparing the incidence ratios of STEMI admissions or procedure/day during both periods. IRR is presented with $95 \%$ confidence intervals $(95 \% \mathrm{Cl})$. The ratio of STEMI deaths and complication rate (in percentage) between the study and control period are shown in the risk ratio (RR) with $95 \% \mathrm{Cls}$.

\section{Statistical analysis}

The continuous data (demographic characteristics and angiographic, procedural, and hospital outcomes) are presented as mean \pm SD and compared using the t-test. Discrete data are shown as counts and proportions and risk ratio (RR) with $95 \% \mathrm{Cl}$ and compared using the chi-squared $\left(X^{2}\right)$ test. Poisson regression (STEMI admissions per day model) was used to calculate the IRR for events including admissions, procedures, between the study and control periods. IRR between the groups is presented with $95 \% \mathrm{Cl}$. A two-sided $p$ value of $<0.05$ is considered to indicate statistical significance. The statistical analysis was performed using the Statistical Package for the Social Sciences released 2012 (IBM Corp, SPSS Statistics for Windows, Version 21.0, Armonk, NY, USA).

\section{RESULTS}

\section{Patient characteristics}

Overall, 373 patients admitted with the diagnosis of STEMI were included in this analysis. Of them, 156 (41.8\%) were admitted during the study period and 217 (58.2\%) during the control period. Baseline data are shown in Table 1. There were no differences between the patients admitted in the study and control periods in terms of sex, age, and cardiovascular risk factors (arterial hypertension, dyslipidemia, diabetes mellitus, and smoking) and previous comorbidities.

Admission and procedural findings for STEMI during the COVID-19 and control periods

The admissions for STEMI in the study period reduced by $28.1 \%$ compared with the control period representing IRR $=0.719$ (95\% Cl 0.51-0.95), $p=0.033$. A typical $U$ curve was observed for STEMI admissions from similar numbers during the first week to an important reduction by around $59 \%$ throughout 


\begin{tabular}{|c|c|c|c|}
\hline Variables & Control period $\mathbf{n = 2 1 7}(\%)$ & Study period $n=156(\%)$ & $P$-value* \\
\hline Male & $153(73 \%)$ & $121(78 \%)$ & 0.160 \\
\hline Age, years (SD) & $66.56(11.46$ & $65.22(11.73)$ & 0.271 \\
\hline Diabetes mellitus & $104(47.9 \%)$ & $68(43.8 \%)$ & 0.469 \\
\hline Hypertension & $189(87.1 \%)$ & $139(89.7 \%)$ & 0.670 \\
\hline Dyslipidemia & $119(54.8 \%)$ & $86(55.5 \%)$ & 0.955 \\
\hline Familiar history for CAD & $51(23.5 \%)$ & $21(13.5 \%$ & 0.022 \\
\hline Smoking & $88(40.6 \%)$ & $56(36.1 \%)$ & 0.422 \\
\hline Previous MI & $29(13.4 \%)$ & $15(9.7 \%)$ & 0.345 \\
\hline Previous PCl & $17(7.8 \%)$ & $7(4.5 \%)$ & 0.278 \\
\hline Previous CABG & $3(1.4 \%)$ & $4(2.6 \%)$ & 0.658 \\
\hline Previous CAD & $27(12.4 \%)$ & $12(7.7 \%)$ & 0.191 \\
\hline Dilated CMP & $10(4.6 \%)$ & $2(1.3 \%)$ & 0.134 \\
\hline Impaired renal function & $31(14.3 \%)$ & $21(13.5 \%)$ & 0.940 \\
\hline Previous stroke & $12(5.5 \%)$ & $12(7.7 \%)$ & 0.531 \\
\hline Anterior infarction ( $n$, STEMl\%) & $102(47 \%)$ & $85(54.5 \%)$ & 0.187 \\
\hline Inferior (lateral posterior) infarction ( $\mathrm{n}$, STEMI\%) & $115(53 \%)$ & $71(45.5 \%)$ & 0.187 \\
\hline Symptom onset to ICU time (SD) & $438.73(385)$ & $925.65(1097)$ & $<0.001$ \\
\hline Symptom onset $<6 \mathrm{~h}$ (early) & $126(58.1 \%)$ & $69(44.2 \%)$ & 0.011 \\
\hline Symptom onset $6-12 \mathrm{~h}$ (delayed) & $58(26.7 \%)$ & $34(21.8 \%)$ & \\
\hline Symptom onset >12 h (late) & $33(15.2 \%)$ & $53(34 \%)$ & \\
\hline Coronary angiography & $199(91.7 \%)$ & $140(89.7 \%)$ & 0.641 \\
\hline Refused coronary angiography & $13(6 \%)$ & $11(7.1 \%)$ & 0.825 \\
\hline Died before consent for coronary angiography & $5(2.3 \%$ & $5(3.2 \%)$ & 0.836 \\
\hline CAD (n, angiography\%) & $196(98.5 \%)$ & $138(98.6 \%)$ & 0.950 \\
\hline 1 vessel CAD ( $n$, angiography $\%)$ & $53(26.3 \%)$ & $41(29.3 \%)$ & 0.678 \\
\hline 2 vessel CAD ( $n$, angiography\%) & $80(40.2 \%)$ & $42(30 \%)$ & 0.070 \\
\hline 3 vessel CAD ( $n$, angiography $\%)$ & $62(31.2 \%)$ & $56(40 \%)$ & 0.117 \\
\hline LM disease (n, angiography\%) & $15(7.5 \%)$ & $24(17.1 \%)$ & 0.011 \\
\hline No critical stenoses ( $\mathrm{n}$, angiography\%) & $3(1.5 \%)$ & $2(1.4 \%)$ & 0.950 \\
\hline $\mathrm{PCl}(n, \%)$ & $168(77.4 \%)$ & $113(72.4 \%)$ & 0.327 \\
\hline $\operatorname{PPCl}(n, \%)$ & $146(67.3 \%)$ & $90(57.7 \%)$ & 0.074 \\
\hline $\mathrm{PPCl}(<12 \mathrm{~h})$ & $146(79.3 \%)$ & $90(87.4 \%)$ & 0.122 \\
\hline PCl of LAD $(n, \%)$ & $110(65.5 \%)$ & $71(62.8 \%)$ & 0.740 \\
\hline $\mathrm{PCl}$ of $\operatorname{LCX}(n, \%)$ & $41(24.4 \%)$ & $22(19.5)$ & 0.408 \\
\hline $\mathrm{PCl}$ of RCA $(n, \%)$ & $80(47.6 \%)$ & $49(43.4 \%)$ & 0.500 \\
\hline CABG recommended $(n, \%)$ & $30(13.8 \%)$ & $29(18.6 \%)$ & 0.271 \\
\hline CABG performed $(n, \%)$ & $5(2.3 \%)$ & $13(8.3 \%)$ & 0.043 \\
\hline CAD with medical treatment $(n, \%)$ & $6(2.7 \%)$ & $5(3.2 \%)$ & 0.804 \\
\hline
\end{tabular}

*To determine the statistical significance for comparison regarding each of the demographic characteristics, angiographic and procedure-related variables were summarized using mean \pm SD for continuous variables compared using $t$-tests and frequency and percentage for categorical variables compared using chi-squared $\left(X^{2}\right)$ tests.

SD - standard deviation; STEMI - ST-segment elevation myocardial infarction; CAD - coronary artery disease; PCI - percutaneous coronary intervention; CABG - coronary artery bypass grafting; CMP - cardiomyopathy; LM - left main; LAD - left anterior descending; LCx - left circumflex; RCA - right coronary artery

the third to the fifth weeks and returning to a similar range on the seventh week of the study (Fig. 1a and Table 2).

The number of patients undergoing coronary angiography during the study period reduced by $31 \%$ when compared with that in the control period, representing an IRR $=0.69$ (0.47$0.95), p=0.039$. The number of patients undergoing $\mathrm{PCl}$ was also reduced by $33 \%$ during the COVID-19 period, compared with the control period representing an $I R R=0.67(0.43-0.89)$ $\mathrm{p}=0.021$ (Fig. 1b, Table 2). During both study and control periods, there were no significant differences in the propor- tion of patients undergoing coronary angiography $(89.7 \%$ vs. $91.7 \%)$ and $\mathrm{PCl}(72.4 \%$ vs. $77.4 \%)$; however, there was a trend in which the proportion of patients undergoing primary $\mathrm{PCI}$ was smaller during the COVID-19 period $(57.7 \%$ vs. $67.3 \%$, $\mathrm{p}=0.074$ ) but not quite significant. There were no differences in the proportion of patients recommended for CABG $(20.7 \%$ vs. $15.1 \%)$ but with a significant increase of patients undergoing CABG during the COVID-19 period $(9.3 \%$ vs. $2.5 \%$ $p=0.013)$. The frequency of left main involvement $(17.1 \%$ vs $7.5 \%, p=0.011$ ) was higher among the patients in the study 
period than in the control period. In both the study groups, the left anterior descending artery (LAD) was the most commonly treated vessel, but without any significant differences between the groups (Table 1).
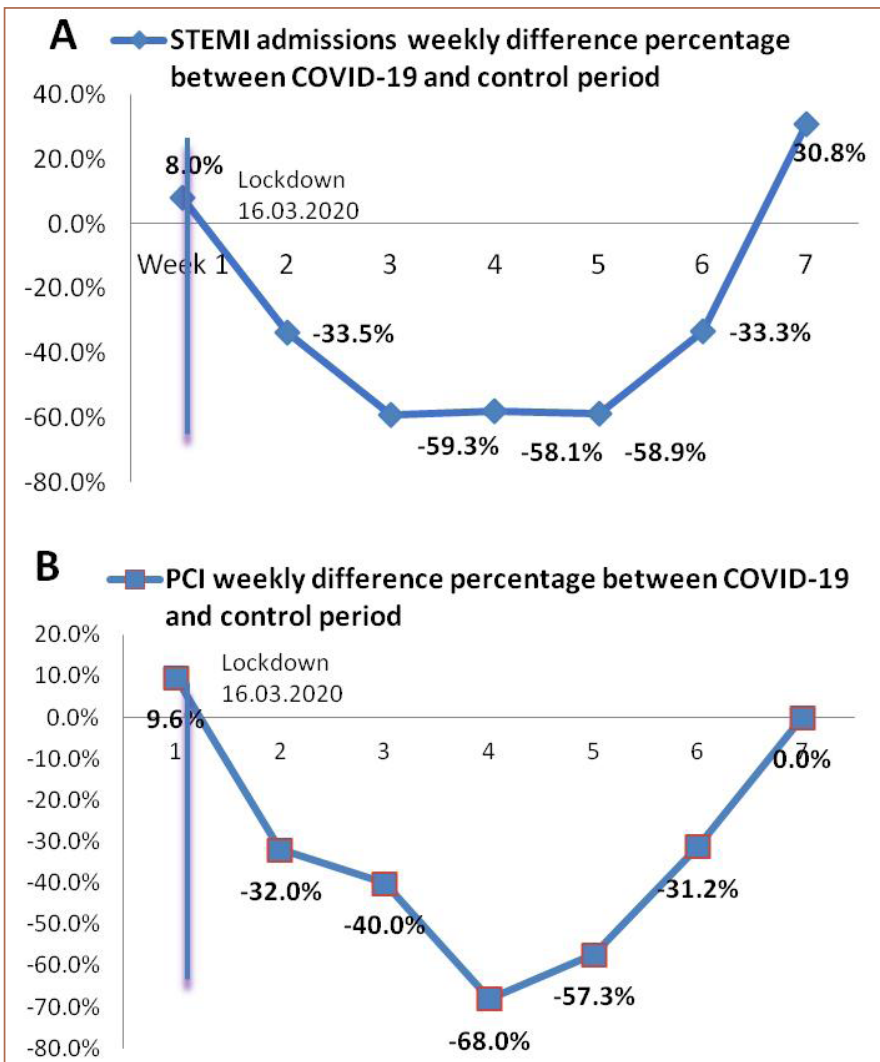

\section{C $\leadsto$ Weekly percentage differences in in-hospital deaths between COVID-19 and study period}

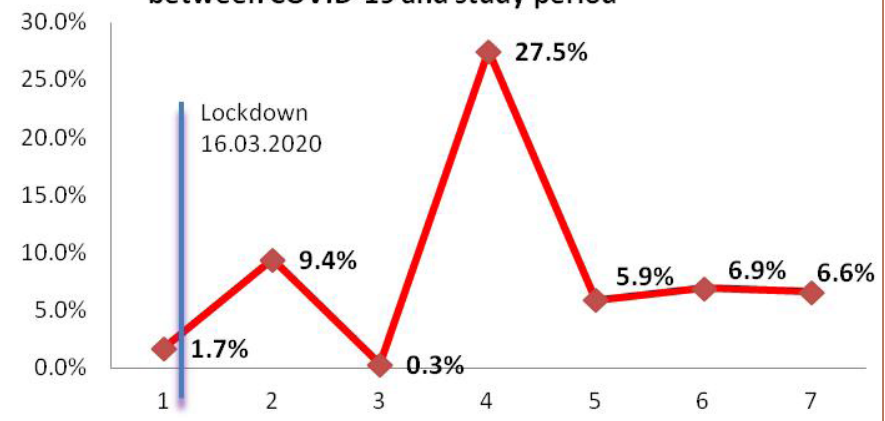

Figure 1. a) Weekly admission difference in percentage (percentage change during COVID-19 compared with the control period) assessed for ST-segment elevation myocardial infarction showing an important reduction in all admissions during the third to fifth weeks of the study compared with that in the control period. b) Weekly difference in percutaneous coronary interventions percentage (percentage change during COVID-19 and control periods) showing an important reduction during the third to fifth weeks of the study compared to that in the control period. c) Weekly difference in in-hospital mortality percentage (percentage change during COVID-19 and control periods) showing an important increase during the fourth week of the study compared to that in the control period.
Symptom onset to the intensive care unit time

During the study period compared with the control period, not only was there a reduction in admissions, but also the patients presented later from symptom onset to our ICU, (925.6 \pm 1097 vs. $438.7 \pm 385$ minutes, $p<0.001)$. A significant reduction in the number of patients presenting less than 6 hours from symptom onset $(44.2 \%$ vs. $58.1 \%, p=0.011)$ and $a$ significant increase in the number of patients presenting over 12 hours from symptom onset (34\% vs. $15.2 \%$, $p<0.001$ ) was observed during the COVID-19 pandemic period (Table 1 and Fig. 2a).

\section{In-hospital outcomes}

In-hospital outcomes are shown in Tables 3 and 4 and Figures $1 c, 2 b$, and $2 c$. The death rate owing to STEMI during the pandemic period was significantly increased to $14.1 \%$ from $7.8 \%$ during the control period $[R R=1.91$ (95\% Cl 1.039-3.52), $\mathrm{p}=0.037]$. The incidence of cardiogenic shock also increased during the pandemic at $21.2 \%$ versus $12.4 \%$ in 2019 [ $R R=1.70$ (95\% Cl1.07-2.71), $\mathrm{p}=0.025$ ]. There is a trend of greater death rate in patients undergoing primary $\mathrm{PCl}$ during 2020 than in 2019 , but without reaching significance [ $8.9 \%$ vs. $4.8 \%$, $\mathrm{RR}=1.85(95 \% \mathrm{Cl} 0.69-4.94), \mathrm{p}=0.217]$. The increase in death rates owing to STEMI is associated as mentioned above with longer time from symptom onset to ICU with higher cTnI on admission ( $36 \pm 55.1$ vs. $21.96 \pm 49.9 \mathrm{ng} / \mathrm{mL}, \mathrm{p}=0.014$ ) and lower ejection fraction ( $42.3 \pm 9.59$ vs. $44.9 \pm 8.90 ; p=0.007)$ among patients admitted during the study period compared with those in the control period. However, the time between ICU arrival and sheath insertion in patients with STEMI was shorter $(48.3 \pm 24.9$ vs. $57.2 \pm 33.2, p=0.04)$, and the length of hospital stay was shorter $(4.63 \pm 2.58$ vs. $5.98 \pm 3.17, \mathrm{p}<0.001)$.

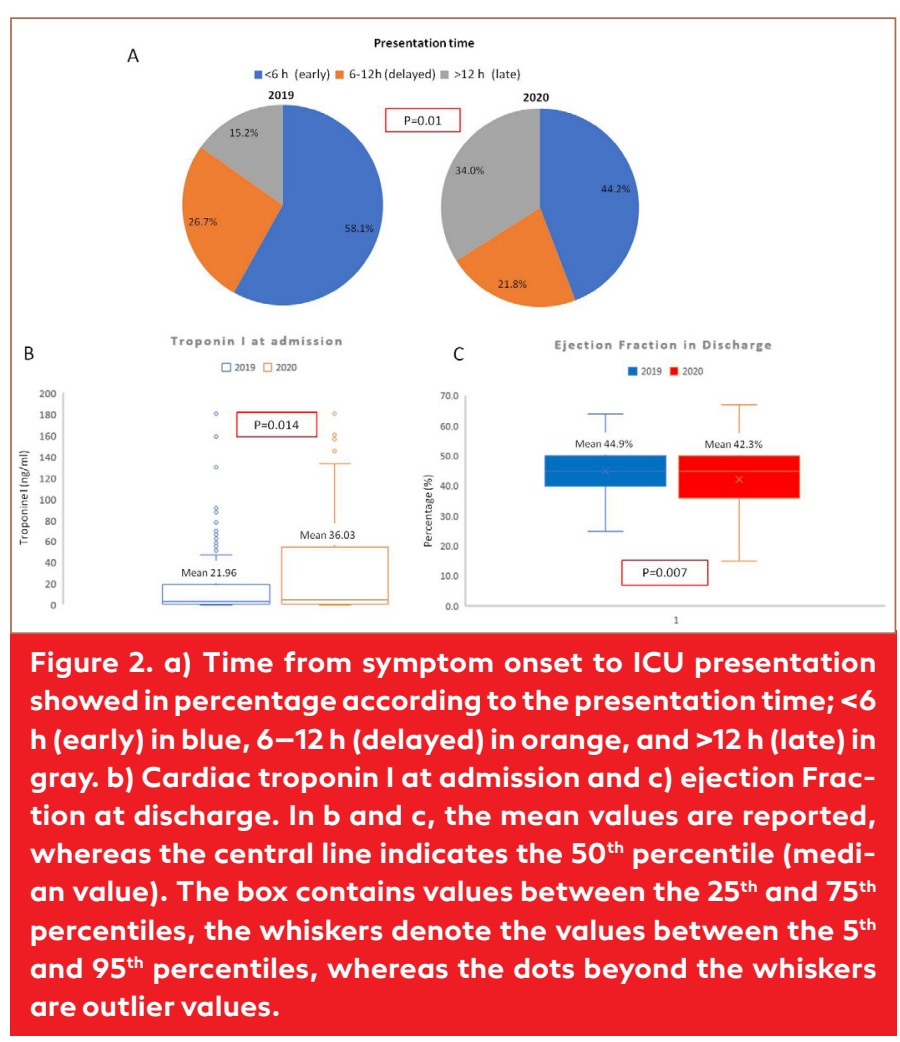


Table 2. Incidence rate ratio of admissions and invasive procedures

Admission presentation and procedures

\begin{tabular}{cccc} 
COVID-19 & Control & Incidence rate ratio (IRR) $\left(95 \% \mathrm{CI}^{\dagger}\right.$ & $\boldsymbol{P}^{\dagger}$-value* $^{*}$ \\
\hline 156 & 217 & $0.719(0.51-0.95)$ & 0.033 \\
$140(89.7 \%)$ & $199(91.7 \%)$ & $0.69(0.47-0.95)$ & 0.039 \\
$113(77.4 \%)$ & $168(72.4 \%)$ & $0.67(0.43-0.89)$ & 0.021 \\
\hline
\end{tabular}

STEMI ( $n)$

Angiography ( $n$, patients \%)

$113(77.4 \%) \quad 168(72.4 \%)$

$0.67(0.43-0.89)$

0.021

${ }^{\dagger}$ Incidence rate ratio (IRR) for STEMI admissions, angiography, PCl obtained from the analyses of 7 weeks in COVID-19 and control period is expressed in IRR and $95 \% \mathrm{CI}$.

*To determine statistical significance for the comparison regarding STEMI admissions and each procedure, the Poisson regression (STEMI admissions/procedure per day model) was used.

STEMI - ST-segment elevation myocardial infarction; $\mathrm{PCl}$ - percutaneous coronary intervention

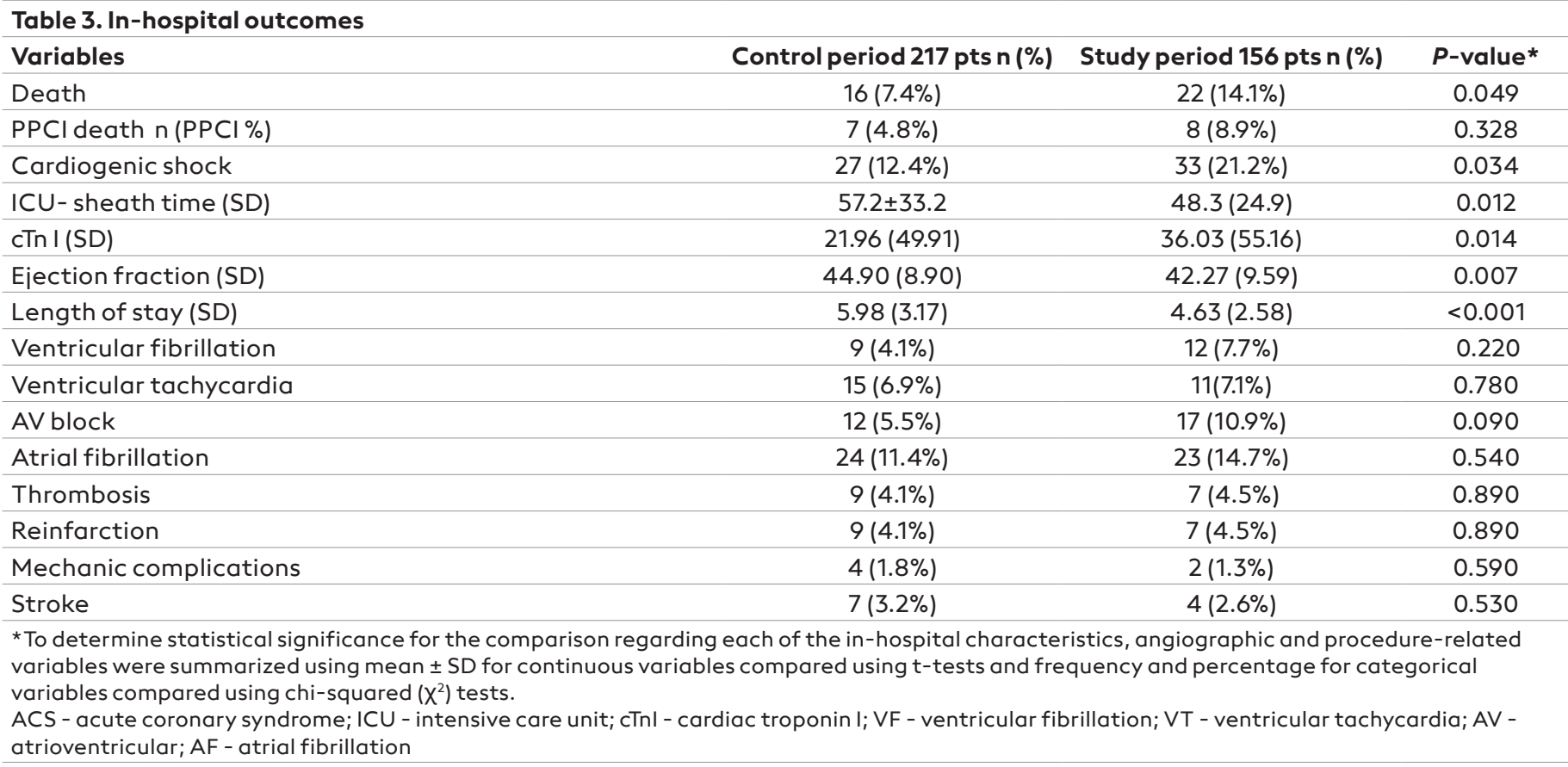

Table 4. Risk ratios for major complications

\begin{tabular}{lcccc}
\hline Complications & COVID-19 (n=156) & Control (n=217) & Risk ratio (RR) (95\% CI) $^{\dagger}$ & P-value * $^{*}$ \\
\hline Death n (patients \%) & $22(14.1 \%)$ & $16(7.4 \%)$ & $1.91(1.04-3.52)$ & 0.037 \\
\hline PPCI death n (PPCI \%) & $8(8.9 \%)$ & $7(4.8 \%)$ & $1.85(0.69-4.94)$ & 0.217 \\
\hline CSH n (patients \%) & $33(21.2 \%)$ & $27(12.4 \%)$ & $1.70(1.07-2.70)$ & 0.025
\end{tabular}

${ }^{t}$ Risk ratio (RR) for death, PPCl death, and cardiogenic shock STEMI obtained from the comparison of event rate (death/CSH) between the COVID-19 and control periods and expressed in RR and $95 \% \mathrm{Cl}$.

$\mathrm{PPCl}$ - primary percutaneous coronary intervention, $\mathrm{CSH}$ - cardiogenic shock

\section{DISCUSSION}

Our study investigated the impact of the COVID-19 pandemic outbreak on STEMI admissions, related invasive procedures, and in-hospital outcomes. We documented a significant reduction in patients with STEMI in COVID-19 compared with those in the control period associated with a significant reduction in the number of patients undergoing coronary angiography and $\mathrm{PCl}$; late presentation and delayed reperfusion therapy associated with greater myocardial damage; and a significant increase in in-hospital mortality and other complication rates.

Hospitalization and in-hospital management of patients with STEMI

The decline in admissions because of STEMI (28.1\%) during COVID-19 compared with those during the control period at our center is consistent with other contemporary reports published worldwide. In studies conducted in Turkey, Kundi et al. (24) found a $58.3 \%$ decrease in admissions for acute myocardial infarction at the Ankara City Hospital (24); and Erol et al. (11) in a nationwide study found a $31.2 \%$ reduction in STEMI comparing the non-pandemic period (TURKMI 1) with the pandemic period (TURKMI 2) (11). In Italy, De Rosa et al. (9) found a $26.5 \%$ reduction in STEMI, $24 \%$ reduction was reported in Greece (14), and a $24 \%$ reduction was reported from the French Cohort of Myocardial Infarction Evaluation (FRENCHIE) registry (13), along with a similar reduction in England at $23 \%$ (12).

Congruent to other studies, we documented a reduction of coronary angiography $(31 \%)$ and $\mathrm{PCl}(33 \%)$ in patients with STEMI. Reports from the US cardiac catheterization labora- 
tories estimated a $38 \%$ reduction in STEMI activations (16), whereas a $40 \%$ reduction was observed in Spain (17), 31\% reduction in primary $\mathrm{PCl}$ in Greece (14), and $21 \%$ reduction in $\mathrm{PCI}$ for STEMI in England (12).

The greatest reduction of admissions and procedures happened during the third to the fifth week of lockdown, with $59.3 \%$ reduction in admissions in the third week and $68 \%$ reduction in $\mathrm{PCl}$ during the fourth week. The increasing trend of numbers started in the sixth week; and in the seventh week, the numbers were similar to the first week of the study, which might reflect a restoration of the normal trend in STEMI compared with the same period of time in 2019.

In Albania, where there was little spread of the virus (5) and no change in the structural and personnel organization of hospital cardiology services, there were no significant differences in the proportion of patients undergoing coronary angiography $(89.7 \%$ vs. $91.7 \%)$ and $\mathrm{PCl}(72.4 \%$ vs. $77.4 \%)$ during both the study and control periods.

There was a trend to a greater number of patients recommended for CABG $(20.7 \%$ vs. $15.1 \%$, $p=0.271)$ even though it was not statistically significant; however, there was a significant increase in patients undergoing CABG during the COVID-19 period $(9.3 \%$ vs. $2.5 \%, \mathrm{p}=0.013)$. One explanation for this could be a possible increase in urgent CABG related to a greater percentage of patients who presented with high-risk coronary anatomy (LM disease) during the COVID-19 pandemic. The late presentation of patients with STEMI (>12 h) possibly shifted the revascularization recommendation toward CABG for full revascularization versus treating the culprit lesion as it was not considered a primary $\mathrm{PCl}$ anymore. The planned interventions were canceled in the cardiosurgery service during the pandemic period, and only emergent or urgent interventions were performed creating greater availability of free operating rooms and staff during the weeks of lockdown.

There are several suggested reasons for the reduction in STEMI admissions during the COVID-19 pandemic. In Albania, the pandemic did not affect the cardiology hospital services; therefore, we strongly believe that the fear of catching the virus was the most important factor which led to ignoring or postponing the seeking of medical care and therefore in the reduction of STEMI admissions and delayed presentation. The call of STAY AT HOME from the authorities and all restrictive measures also led to a probable avoidance of seeking medical care. Another reason could be a lack of physical activity converted into fewer physical triggers for ischemic heart disease.

The first measure mitigation (relaxation of movement restriction and police hour) (22) which began during the seventh week of lockdown and consequent increase in physical activity might have impacted the reverse and increase in STEMI admissions. Possible psychosocial factors (25) such as stressful situations, lost jobs, and so forth accumulating during the weeks of lockdown might have influenced the admissions to increase during the last weeks of the study period.
Late presentation and delayed reperfusion therapy associated with greater myocardial damage

Our study documented that the time from symptom onset to presentation to our ICU for patients with STEMI was higher (including first medical contact (FMC) time and all urban and regional transportation time taken together). The percentage of patients presenting earlier than 6 hours was lower, and the percentage presenting over 12 hours was significantly greater during the pandemic period, partly explaining why a smaller proportion of patients underwent primary $\mathrm{PCl}$ during COVID-19 compared with that in the control period $(57.7 \%$ vs. $67.3 \%, p=0.074)$. The longer presentation time could be because of the late presentation of the patients in emergency services or regional hospitals because of fear of contagion, lockdown, and restriction of movements and also as a function of delayed transportation in Tirana and other regions of Albania to our center as the unique reference center for primary $\mathrm{PCl}$. All these factors may have resulted in a longer time of presentation, and more importantly a longer time of reperfusion through primary $\mathrm{PCl}$, reducing the possible benefits obtained from early reperfusion. During the pandemic period, because of reduced admissions and work volumes in the catheterization laboratory, the ICU sheath time was reduced; however, its effect was neutralized by longer symptom onset to ICU time, consequently without having an impact on the total ischemic time. The later presentation of patients with STEMI is also documented in other studies. Erol et al. (11) showed a significant delay in the treatment of patients presenting with STEMI (an increase in the time from symptom onset to hospital arrival) (185 min vs. 150 min $p<0.001$ ). British investigators (26) documented a significant increase in symptom onset time to FMC during COVID-19 compared to that in the pre-COVID group [227 min (65-790) vs. $119 \mathrm{~min}(27-203), p=0.01]$. A significant increase in symptom onset to FMC time was also reported in Ireland (27), France (28), the Lombardy region in Italy $(29,30)$, and Hubei Region in China (31). The increase in the FMC time in Northern Italy $(29,30)$, and in China (31) (specific region as mentioned above) is also attributed to the severity of the COVID-19 pandemic during the first months of the outbreak along with the influence of different factors related to possible healthcare system deficits and the fear of catching the virus in healthcare structures.

Contrary to our findings, a multicentric study (FITT-STEMI) conducted in Germany documented no differences in symptom onset to FMC time and emergency and transportation time showing that the STEMI network and all structures overcame the pandemic challenge successfully (21).

Our patients admitted with STEMI during the COVID-19 outbreak presented with worsening conditions, such as longer time from symptom onset to ICU, higher troponin I levels (a marker of delayed presentation), and lower left ventricular ejection fraction (an indicator of greater myocardial injury). Our findings are congruent to other single-center studies conducted in the UK $(32)$ and Germany $(33,34)$ regarding high cTnl on presentation and studies conducted in Turkey (11), Greece (14), Ireland (24), Germany (33), and UK (32) regarding lower LVEF at hospital discharge. 
The effect of deferred or late presentation of patients with STEMI during the COVID-19 pandemic associated with a greater myocardial injury (lower left ventricular ejection fraction) conceivably will be observed in the future in terms of morbidity and mortality.

\section{Mortality and complications}

In our study, we observed a significant increase in the rates of mortality $(R R=1.91, p=0.037)$ and cardiogenic shock $(R R=1.7$, $\mathrm{p}=0.025$ ) during COVID-19 compared with those in the control period. We believe this is explained by the late presentation and greater myocardial injury. The delayed and late MI presentation are the possible reasons for increased in-hospital mortality, explained also by the fact that during both periods there were no differences in the percentage of patients undergoing coronary angiography and $\mathrm{PCl}$. There is no significant increase in the STEMI mortality of patients undergoing primary $\mathrm{PCl}[\mathrm{RR}=1.85$ (95\% Cl 0.69-4.94), $\mathrm{p}=0.217]$ and a decrease as mentioned in the ICU sheath time during the pandemic period at our center. The benefits of perfusion therapy ( $\mathrm{PCl}$ ) would be greater if performed in time, reducing myocardial damage, and consequently heart failure and mortality in our patients.

Relevant discrepancies in mortality and complication rates are found between studies in different countries and centers. Several studies, mainly from COVID-19 epicenters, have reported that patients with STEMI had higher in-hospital mortality and complication rate. In Italy, the study conducted by De Rosa et al. (9) showed that STEMI case fatality rate during the pandemic was substantially increased compared with that in 2019 ( $R R=3.3, p<0.001)$. Similarly in a study by Trabattoni et al. (29), the in-hospital mortality in patients admitted late with $\mathrm{AMI}$ increased to $38 \%$ from $10 \%$. Increase in mortality rates was also observed in the Hubei province, China, from $4.6 \%$ to $7.3 \%$ during the outbreak period (24), in the USA (18), and Hong Kong (20).

Results from a multicentric study conducted in Germany (21) demonstrated that the in-hospital mortality was similar $(9.2 \%$ vs. $8.5 \%, p=0.074)$. In Denmark (19), the adjusted STEMI mortality (OR 1.04, 0.68-1.59) and the incidence of AMI-cardiogenic shock [5.8\% (2015-19) vs. 5.9\% (2020 lockdown)] was comparable between periods showing that the resources of the healthcare systems and logistic structures, especially the intensive care units preserved a high quality of standards even in the challenging pandemic period. In Turkey, the results from the abovementioned nationwide study (11) showed similar in-hospital mortality for STEMI comparing the pre-pandemic and pandemic periods $(5.3 \%$ vs. $4.7 \%$, $p=0.642$ ); however, in-hospital major adverse cardiac events (in-hospital mortality, heart failure, and cardiogenic shock) were significantly increased during the pandemic period [OR=2.08 (1.38-3.13), $\mathrm{p}<0.001]$.

In a recent systematic review and meta-analysis, Rattka et al. (35) demonstrated globally that in-hospital mortality of the post-COVID-19 group was not significantly higher than the pre-pandemic group, although in some pandemic epicenters, included in the analysis, there was an increase in mortality.
We found a reduction of STEMI admissions, related invasive revascularization procedures, and an increase in STEMI in-hospital mortality and complications, creating a full view of all the collateral damage caused by the COVID-19 pandemic in Albania. We demonstrated a delayed admission of patients with STEMI and as a consequence greater myocardial damage, an increase in cardiac troponin I, and lower LVEF leading to greater, but avoidable in-hospital mortality and complications. This collateral damage owing to the pandemic (patients with STEMI not presenting or presenting late to the hospital) will create further pressure on the public health system in terms of morbidity, disability, and mortality.

Public information encouraging people not to avoid necessary medical care and COVID-19 safe healthcare services are the key challenges in dealing with the situation created by the pandemic.

\section{Strength and limitations}

This study included all the consecutive patients admitted with STEMI to our center in two different periods [pre-pandemic and pandemic (lockdown)] presenting the entire view of management, invasive treatment, and complications; however, ours was a retrospective study, and all data were taken from medical files with possible known biases (36).

As a reference center, the largest tertiary public center, all the patients with STEMI throughout Albania (regional hospitals) are normally transferred here. The proportion of patients transferred versus those treated in hospitals in the local counties during the pandemic remains unknown. Our study did not include patients diagnosed (or suspected) with COVID-19 because these patients were hospitalized in COVID-19 hospitals equipped with a catheterization laboratory.

\section{CONCLUSION}

Hospitalizations and related invasive revascularization procedures for STEMI significantly reduced during the COVID-19 pandemic. A significant increase in STEMI mortality and cardiogenic shock was observed during the pandemic outbreak. Delayed timely reperfusion by primary $\mathrm{PCI}$ might be responsible for the increased risk for complications. Public information encouraging people not to avoid required medical care and safe and COVID-19 free healthcare services are the key challenges in this pandemic.

Declaration: It was presented as abstract presentation at the ESC Preventive Cardiology 2021 Congress held as on-line event between 15-17 April 2021.

Conflict of interest: None declared.

Peer-review: Externally peer-reviewed.

Author contributions: Concept - L.S.; Design - L.S., I.A., A.D.; Supervision - A.D., A.G.; Fundings - None; Materials - L.S., M.G., A.C., E.T.; Data collection \&/or processing - L.S., I.A., M.G., A.C., E.T.; Analysis \&/or interpretation - L.S., I.A., M.G., A.C.; Literature search L.S.; Writing - L.S., M.G., A.C.; Critical review - A.D., A.G. 


\section{REFERENCES}

1. World Health Organization. Novel coronavirus-China. Date: Jan 12, 2020, Last accessed: April 19. Available at: URL: http:/ www.who.int/csr/don/12-january-2020-novel-coronavirus-china/en/ 2021

2. World Health Organization. Coronavirus disease 2019 situation report. Last accessed: April 19, 2021. Available at: URL: https:/ www.who.int/emergencies/diseases/novel-coronavirus-2019/ situation-reports/

3. 9 Mars 2020/ Informacion i përditësuar për Koronavirusin COVID-19. Last accessed April 23, 2021 - in Albanian. Available at: URL: https://shendetesia.gov.al/9-mars-2020-informacion-i-perditesuar-per-koronavirusin-covid_19/

4. Për marrien e masave të veçanta në parandalimin e përhapjes së infeksionit të shkaktuar nga covid-19 (order of minister of health and social protection) (Last accessed March 3, 2021-in Albanian). Available at: URL: https://qbz.gov.al/ eli/urdher/2020/03/10/156/ef6f88e4-2dde-4c03-86d8dca1d58275d5

5. Last accessed March 5, 2021 - in Albanian. Available at: URL: https://coronavirus.al/statistika/

6. Lodigiani C, lapichino G, Carenzo L, Cecconi M, Ferrazzi P, Sebastian T, et al.; Humanitas COVID-19 Task Force. Venous and arterial thromboembolic complications in COVID-19 patients admitted to an academic hospital in Milan, Italy. Thromb Res 2020; 191: 9-14. [Crossref]

7. Modin D, Claggett $B$, Sindet-Pedersen $C$, Lassen $M C H$, Skaarup KG, Jensen JUS, et al. Acute COVID-19 and the Incidence of Ischemic Stroke and Acute Myocardial Infarction. Circulation 2020; 142: 2080-2. [Crossref]

8. Pessoa-Amorim G, Camm CF, Gajendragadkar P, De Maria GL, Arsac C, Laroche $C$, et al. Admission of patients with STEMI since the outbreak of the COVID-19 pandemic: a survey by the European Society of Cardiology. Eur Heart J Qual Care Clin Outcomes 2020; 6: 210-6. [Crossref]

9. De Rosa S, Spaccarotella C, Basso C, Calabrò MP, Curcio A, Filardi PP, et al.; Società Italiana di Cardiologia and the CCU Academy investigators group. Reduction of hospitalizations for myocardial infarction in Italy in the COVID-19 era. Eur Heart J 2020; 41: 2083-8. [Crossref]

10. De Filippo O, D'Ascenzo F, Angelini F, Bocchino PP, Conrotto F, Saglietto A, et al. Reduced Rate of Hospital Admissions for ACS during Covid-19 Outbreak in Northern Italy. N Engl J Med 2020; 383: 88-9. [Crossref]

11. Erol MK, Kayıkçıoğlu M, Kılıçkap M, Güler A, Yıldırım A, Kahraman $F$, et al. Treatment delays and in-hospital outcomes in acute myocardial infarction during the COVID-19 pandemic: A nationwide study. Anatol J Cardiol 2020; 24: 334-42. [Crossref]

12. Mafham MM, Spata E, Goldacre R, Gair D, Curnow P, Bray M, et al. COVID-19 pandemic and admission rates for and management of acute coronary syndromes in England. Lancet 2020; 396: 381-9. [Crossref]

13. Mesnier J, Cottin Y, Coste P, Ferrari E, Schiele F, Lemesle G, et al. Hospital admissions for acute myocardial infarction before and after lockdown according to regional prevalence of COVID-19 and patient profile in France: a registry study. Lancet Public Health 2020; 5: e536-42. [Crossref]

14. Papafaklis MI, Katsouras CS, Tsigkas G, Toutouzas K, Davlouros $P$, Hahalis $G N$, et al. "Missing" acute coronary syndrome hospitalizations during the COVID-19 era in Greece: Medical care avoidance combined with a true reduction in incidence? Clin Cardiol 2020; 43: 1142-9. [Crossref]

15. Roffi M, Capodanno D, Windecker S, Baumbach A, Dudek D. Impact of the COVID-19 pandemic on interventional cardiology practice: results of the EAPCI survey. Eurolntervention 2020; 16 : 247-50. [Crossref]

16. Garcia S, Albaghdadi MS, Meraj PM, Schmidt C, Garberich R, Jaffer FA, et al. Reduction in ST-Segment Elevation Cardiac Catheterization Laboratory Activations in the United States During COVID-19 Pandemic. J Am Coll Cardiol 2020; 75: 2871-2. [Crossref]

17. Rodriguez-Leor O, Cid-Alvarez B, Ojeda S, Martin-Moreiras J, Rumoroso JR, Lopez-Palop Ramon, et al. Impact of the COVID-19 pandemic on interventional cardiology activity in Spain. REC Interv Cardiol 2020; 2: 82-9. [Crossref]

18. Krasne M, Gluckman TJ, Marine JE, Blumenthal RS, Sharma G. Outcomes of Acute Myocardial Infarction hospitalizations during the COVID-19 Pandemic (Last accessed March 5, 2021). Available at: URL: https://www.acc.org/latest-in-cardiology/ articles/2020/08/24/09/38/outcomes-of-acute-myocardial-infarction-hospitalizations-during-the-covid-19-pandemic

19. Lauridsen MD, Butt JH, Østergaard L, Møller JE, Hassager C, Gerds T, et al. Incidence of acute myocardial infarction-related cardiogenic shock during corona virus disease 19 (COVID-19) pandemic. Int J Cardiol Heart Vasc 2020; 31: 100659. [Crossref]

20. Tam CF, Cheung KS, Lam S, Wong A, Yung A, Sze M, et al. Impact of coronavirus disease 2019 (COVID-19) outbreak on outcome of myocardial infarction in Hong Kong, China. Catheter Cardiovasc Interv 2021; 97: E194-7. [Crossref]

21. Scholz KH, Lengenfelder B, Thilo C, Jeron A, Stefanow S, Janssens $U$, et al. Impact of COVID-19 outbreak on regional STEMI care in Germany. Clin Res Cardiol 2020; 109: 1511-21. [Crossref]

22. Lehtësimi i masave, Manastirliu: Nga e hëna fasha e lëvizjes zgjerohet në 2 orë Fjala e plotë e ministres së Shëndetësisë dhe Mbrojtjes Sociale Ogerta Manastirliu". shendetesia.gov.al. (Last accessed March 5, 2021 - in Albanian) 25 April 2020. Available at: URL: https:/new.shendetesia.gov.al/lehtesimi-i-masave-manastirliu-nga-e-hena-fasha-e-levizjes-zgjerohet-ne-2-orefjala-e-plote-e-ministres-se-shendetesise-dhe-mbrojties-sociale-ogerta-manastirliu/

23. Thygesen K, Alpert JS, Jaffe AS, Chaitman BR, Bax JJ, Morrow $D A$, et al. Fourth universal definition of myocardial infarction (2018). Eur Heart J 2019; 3: 237-69. [Crossref]

24. Kundi $H$, Balcı MM, Güngörer B, Yeșiltepe $M$, Coșkun N, Sürel AA. Trends in acute myocardial infarction admissions during the COVID-19 pandemic in Ankara, Turkey. Anatol J Cardiol 2020; 24: 81-2. [Crossref]

25. Möller J, Theorell T, de Faire U, Ahlbom A, Hallqvist J. Work related stressful life events and the risk of myocardial infarction. Case-control and case-crossover analyses within the Stockholm heart epidemiology programme (SHEEP). J Epidemiol Community Health 2005; 59: 23-30. [Crossref]

26. Abdelaziz HK, Abdelrahman A, Nabi A, Debski M, Mentias A, Choudhury $\mathrm{T}$, et al. Impact of COVID-19 pandemic on patients with ST-segment elevation myocardial infarction: Insights from a British cardiac center. Am Heart J 2020; 226: 45-8. [Crossref]

27. Coughlan JJ, Chongprasertpon N, Arockiam S, Arnous S, Kiernan TJ. COVID-19 and STEMI: A snapshot analysis of presentation patterns during a pandemic. Int J Cardiol Heart Vasc 2020; 30: 100546. [Crossref]

28. Hauguel-Moreau M, Pillière R, Prati G, Beaune $S$, Loeb T, Lannou S, et al. Impact of Coronavirus Disease 2019 outbreak on acute coronary syndrome admissions: four weeks to reverse the trend. J Thromb Thrombolysis 2021; 51: 31-2. [Crossref]

29. Gramegna M, Baldetti L, Beneduce A, Pannone L, Falasconi G, Calvo F, et al. ST-Segment-Elevation Myocardial Infarction During COVID-19 Pandemic: Insights From a Regional Public Service Healthcare Hub. Circ Cardiovasc Interv 2020; 13: e009413. [Crossref] 
30. Trabattoni D, Montorsi P, Merlino L. Late STEMI and NSTEMI Patients' Emergency Calling in COVID-19 Outbreak. Can J Cardiol 2020; 36: 1161.e7-8. [Crossref]

31. Zhang F, Song $X$, Dang Y. Experience of ST Segment Elevation Myocardial Infarction Management During COVID-19 Pandemic From the Mainland of China. Cardiovasc Revasc Med 2021; 28 : 92-4. [Crossref]

32. Wilson SJ, Connolly MJ, Elghamry Z, Cosgrove C, Firoozi S, Lim P, et al. Effect of the COVID-19 Pandemic on ST-Segment-Elevation Myocardial Infarction Presentations and In-Hospital Outcomes. Circ Cardiovasc Interv 2020; 13: e009438. [Crossref]

33. Primessnig $U$, Pieske $B M$, Sherif $M$. Increased mortality and worse cardiac outcome of acute myocardial infarction during the early COVID-19 pandemic. ESC Heart Fail 2021; 8: 333-43. [Crossref]

34. Rattka M, Stuhler L, Winsauer C, Dreyhaupt J, Thiessen K, Baumhardt $M$, et al. Outcomes of Patients With ST-Segment Elevation Myocardial Infarction Admitted During COVID-19 Pandemic Lockdown in Germany - Results of a Single Center Prospective Cohort Study. Front Cardiovasc Med 2021; 8: 638954. [Crossref]

35. Rattka M, Dreyhaupt J, Winsauer C, Stuhler L, Baumhardt $M$, Thiessen K, et al. Effect of the COVID-19 pandemic on mortality of patients with STEMI: a systematic review and meta-analysis. Heart 2020: heartinl-2020-318360. [Crossref]

36. Manja V, Lakshminrusimha S. Epidemiology and Clinical Research Design, Part 1: Study Types. Neoreviews 2014; 15: e55869. [Crossref] 